Review Article

\title{
“Cumulative Stress": The Effects of Maternal and Neonatal Oxidative Stress and Oxidative Stress-Inducible Genes on Programming of Atopy
}

\author{
Sara Manti, ${ }^{1}$ Lucia Marseglia, ${ }^{2}$ Gabriella D'Angelo, ${ }^{2}$ Caterina Cuppari, ${ }^{1}$ Erika Cusumano, ${ }^{2}$ \\ Teresa Arrigo, ${ }^{1}$ Eloisa Gitto, ${ }^{2}$ and Carmelo Salpietro ${ }^{1}$
}

${ }^{1}$ Unit of Pediatric Genetics and Immunology, Department of Pediatrics, University of Messina, 98125 Messina, Italy

${ }^{2}$ Neonatal and Pediatric Intensive Care Unit, Department of Pediatrics, University of Messina, 98125 Messina, Italy

Correspondence should be addressed to Sara Manti; saramanti@hotmail.it

Received 25 January 2016; Revised 27 May 2016; Accepted 22 June 2016

Academic Editor: Daniela Giustarini

Copyright (c) 2016 Sara Manti et al. This is an open access article distributed under the Creative Commons Attribution License, which permits unrestricted use, distribution, and reproduction in any medium, provided the original work is properly cited.

\begin{abstract}
Although extensive epidemiological and laboratory studies have been performed to identify the environmental and immunological causes of atopy, genetic predisposition seems to be the biggest risk factor for allergic diseases. The onset of atopic diseases may be the result of heritable changes of gene expression, without any alteration in DNA sequences occurring in response to early environmental stimuli. Findings suggest that the establishment of a peculiar epigenetic pattern may also be generated by oxidative stress (OS) and perpetuated by the activation of OS-related genes. Analyzing the role of maternal and neonatal oxidative stress and oxidative stress-inducible genes, the purpose of this review was to summarize what is known about the relationship between maternal and neonatal OS-related genes and the development of atopic diseases.
\end{abstract}

\section{Introduction}

Allergic diseases including atopic dermatitis, allergic rhinitis, and asthma are some of the most common chronic diseases in the world [1]. Although extensive epidemiological and laboratory studies have been performed to identify the environmental and immunological causes of atopy, genetic predisposition seems to be the biggest risk factor for allergic diseases $[2,3]$. It is known that several foetal adaptive responses to environmental factors are mediated by epigenetic changes which, impacting early-life morbidity, may exercise effects on the immune system, lung development, airway remodelling, allergen predisposition, and atopic and nonatopic inflammation, through numerous pathways $[2,4]$. In particular, the onset of atopic diseases may be the result of heritable changes of gene expression, without any alteration in DNA sequences, occurring in response to early (prenatal) or later (perinatal) environmental stimuli [4]. Findings suggest that the establishment of a peculiar epigenetic pattern may also be generated by oxidative stress (OS) and perpetuated by the activation of OS-related genes [5]. Reactive oxygen species (ROS), known to be important cell-signalling molecules [6], could, in fact, set up a positive-feedback loop that induces and perpetuates atopic injury. OS, also influencing T-cell signal transduction and gene expression [7], modulates Tcell polarization toward a T helper- (Th-) 2 cellular subset [8] which might be, in turn, a further source of ROS.

OS is a specific setting also occurring in normal events such as pregnancy and birth.

Pregnancy is a physiological period associated with enhanced OS related to high metabolic turnover and elevated tissue oxygen requirements [9]. During pregnancy, increased oxygen demand augments the rate of production of ROS, and women, even during normal pregnancies, experience elevated serum OS levels [9]. Increased OS levels and reduced antioxidative capacities may contribute to the pathogenesis of perinatal $[10,11]$ and postnatal disorders $[12,13]$, such as atopic diseases $[14,15]$, as newborns are more prone to OS than individuals later in life [16]. Moreover, it has also been reported that OS-related maternal genetics, independently of 
transmission of specific alleles, may influence a child's atopic risk beginning in the uterus $[17,18]$.

Also during pregnancy, newborns are also continually exposed to elevated levels of ROS. At birth, newborns transit from a hypoxic intrauterine to a normoxic extrauterine environment. This increased OS further favours neonatal morbidity, also including atopy [14].

Analyzing the role of maternal and neonatal oxidative stress and oxidative stress-inducible genes, the purpose of this review was to summarize what is known about the relationship between maternal and neonatal OS-related genes and the development of atopic diseases.

\section{Cumulative Effects of Maternal and Neonatal Oxidative Stress on the Immune System}

It is well known that OS occurs early in pregnancy and continues in the postnatal period [12]. In particular, pregnancy is associated with enhanced OS related to high metabolic turnover and elevated tissue oxygen requirements [34]. On the other hand, newborns, exhibiting an accelerated production of free radicals and limited antioxidant protection, are also constitutively vulnerable to OS. Therefore, during pregnancy and intrauterine life, many factors such as hypoxia, inflammation, and infections can easily induce overproduction of free radicals (FRs) [11], exceeding the capacity of defensive mechanisms to neutralize them. The release of FRs leads to the oxidation of lipids, proteins, and polysaccharides and to DNA modifications [7-9, 19] which, in turn, increase the susceptibility of rapidly growing tissues to damage [35], as well as modulation of the immune system $[10,36]$.

With regard to the immune system, different immunological responses to ROS production have been reported, depending on environmental oxidative status. While normal ROS amounts have been shown to be important for T-cell function and for adequate, beneficial antimicrobial protection [37], high ROS concentrations can negatively modulate immune system responses leading to inhibited Tcell proliferation [37] and to hyporesponsivity to exogenous and/or endogenous activating stimuli [9]. In particular, OS plays a critical role as a secondary messenger in the initiation and amplification of signalling, miming antigenic effects. The antigen receptors are themselves OS-generating enzymes, contributing further to enhancing the cellular "oxidative burst" against exogenous pathogens as well as neighbouring cells [10], causing autoinflammatory and/or allergic diseases $[17,38]$.

Moreover, it has been suggested that OS, leading to secretion of a variety of proinflammatory cytokines and chemokines [38], elicits a polarized immune response which is closely associated with a breakdown in immune tolerance [39]. In particular, when immunoglobulin- (Ig-) E binds to specific membrane receptors, peripheral blood is activated to produce more superoxide and hydrogen peroxide $\left(\mathrm{H}_{2} \mathrm{O}_{2}\right)$, contributing to elevated environmental OS and sterile inflammation [40] in upper and lower airways [41-43], and in the skin [44]. Furthermore, immune cells, because of higher production of ROS, are themselves particularly sensitive to OS, creating a vicious circle for the production of proinflammatory mediators and supporting a prooxidant status [9]. The activation of both the redox-sensitive transcription factor nuclear factor-kappa B (NF- $\kappa \mathrm{B})$ and activator protein(AP-) 1 and the release of proinflammatory proteins involved in immune response (e.g., interleukin- (IL-) 1, IL-6, tumour necrosis factor- (TNF-) $\alpha$, and interferon- (INF-) $\alpha$, as well as $\mathrm{H}_{2} \mathrm{O}_{2}$ ) are critical events in immunity, promoting stimulusspecific genes expression $[17,38]$. These findings confirm the evidence that foetal immune response is prenatally influenced [45] and that the activation of maternal and neonatal OS-inducible genes may influence a child's atopic risk, early in the uterus [46, 47] (Tables 1, 2, and 3).

\section{Epigenetic Effects on Atopic Predisposition}

Epigenetics refers to information that is heritable through cell division. Epigenetic mechanisms include DNA methylation, chromatin remodelling and noncoding RNA, histone variations, and posttranslational histone modifications [48]. Epigenetic alterations can occur prenatally, perinatally, and later in life during developmental stages, with unique susceptibility to the effects of environmental exposures [48]. Uterine life is the most critical time in developmental programming; when negative environmental exposures occur, the foetal structure and its functions are irreversibly modified and subjects can be predisposed to several diseases, including allergy [49]. T-cellular differentiation into Th1, Th2, Th17, and Treg is influenced by changes in DNA/histone methylation and/or histone acetylation in naive T-cells and in cytokine promoter regions. Thus, the well-known correlation between epigenetic modifications and Th lineage has led to hypothesize that triggers inhibit Th1 and $\mathrm{T}$ regulatory cell differentiation, promote Th2-response, and could favour the risk of atopic predisposition [50]. Although the mechanism of this process is not fully understood, environmental changes, such as microbial burden [51], dietary changes $[52,53]$, and environmental pollutants [54], appear essential to initiate the cascade of epigenetic modifications that stabilize Th2 gene expression [55]. It is also likely that effects of environmental triggers are also mediated by oxidative stress which, by NF- $\kappa \mathrm{B}$-induced expression of proinflammatory cytokines and methylationmediated changing, can induce histone modifications and chromatin remodelling of proinflammatory genes, exercising further implications on foetal immune programming, atopic predisposition, and increased IgE production following allergen sensitization $[49,56]$.

\section{Cumulative Effects of Oxidative Stress-Inducible Genes on the Immune System}

Genetic linkage and transmission alleles analyses have highlighted the important role of oxidative stress-inducible genes on the neonatal immune system response $[26,57]$. In particular, the concurrent presence of higher ROS levels and antigenic exposure has been reported to alter the methylation of $\mathrm{T}$ helper genes [58]. All these changes impair the differentiation 
TABLE 1: Oxidative stress-inducible genes and allergic asthma.

\begin{tabular}{ll}
\hline Gene & Clinical relevance \\
\hline & GSTs conjugate endogenous byproducts of OS with \\
& glutathione, enabling rapid elimination and thus \\
defending tissues against oxidant damage; common & polymorphisms exist in genes coding for various GSTs \\
(GSTP1) & including glutathione S-transferases M1 (GSTM1) and \\
& P1 (GSTP1)
\end{tabular}

Antioxidant defence enzymes (ADE)

Glutamate cysteine ligase (GCLM)

Glutathione peroxidase (GPX1)

Myeloperoxidase (MPO)

NADPH oxidase (CYBA, p22phox subunit)

$\mathrm{NAD}(\mathrm{P}) \mathrm{H}$ : quinone oxidoreductase type 1 (NQO1)

Microsomal epoxide hydrolase (EPHX1)

Glutamate cysteine ligase (GCLM)

\begin{tabular}{|c|c|c|}
\hline Tumor necrosis factor G-308A & $\begin{array}{l}\text { It may have a protective role in asthma pathogenesis, } \\
\text { depending on airway oxidative stress levels }\end{array}$ & {$[22]$} \\
\hline $\begin{array}{l}\text { Methylenetetrahydrofolate reductase (MTHFR) } \\
\text { ORM1-like } 3 \text { (ORMDL3) } \\
\text { Gasdermin A and B (GSDM) }\end{array}$ & $\begin{array}{l}\text { In addition to foetal smoke exposure, it seems to be } \\
\text { associated with lower airway responsiveness, lung } \\
\text { function, and increased risk of transient wheezing, a } \\
\text { phenotype of childhood asthma }\end{array}$ & $\begin{array}{l}{[23]} \\
{[24]} \\
{[25]}\end{array}$ \\
\hline Antioxidant enzyme paraoxonase (PON1) & $\begin{array}{l}\text { It is inversely correlated to plasma total oxidant status } \\
\text { and to severity of asthma }\end{array}$ & [26] \\
\hline $\begin{array}{l}\text { Nuclear factor (NF), erythroid-derived 2-related factor } \\
2 \text { (NRF2) }\end{array}$ & $\begin{array}{l}\text { It has been found to be a critical regulator in protecting } \\
\text { cells and tissues under highly oxidative } \\
\text { microenvironments, including airways that interface } \\
\text { with the external environment and are exposed to } \\
\text { pollutants and other oxidant stressors }\end{array}$ & [27] \\
\hline Toll-like receptor 4 (Tlr4) & $\begin{array}{l}\text { It is associated with } \mathrm{O}_{3} \text {-induced lung inflammation and } \\
\text { increased airway hyperpermeability }\end{array}$ & [28] \\
\hline Heme oxygenase-1 (HMOX-1) & $\begin{array}{l}\text { In addition to ozone exposure, it is responsible for the } \\
\text { onset of allergic asthma }\end{array}$ & [29] \\
\hline $\begin{array}{l}\text { Transforming growth factor- (TGF-) betal C-509T } \\
\text { polymorphism }\end{array}$ & $\begin{array}{l}\text { This genotype is associated with an increased risk of } \\
\text { asthma in addition to maternal smoking exposure in } \\
\text { the uterus or to traffic-related emissions }\end{array}$ & {$[30]$} \\
\hline Arginases (ARG1 and $A R G 2)$ & $\begin{array}{l}\text { It may play an important role in asthma pathogenesis } \\
\text { through effects on nitrosative stress }\end{array}$ & {$[31]$} \\
\hline
\end{tabular}

TABLE 2: Oxidative stress-inducible genes and allergic rhinitis.

\begin{tabular}{lll}
\hline Gene & Clinical relevance & References \\
\hline $\begin{array}{l}\text { Glutathione S-transferases- (GSTs-) 1 } \\
\text { polymorphism }\end{array}$ & $\begin{array}{l}\text { It may exert protective effects in allergic } \\
\text { rhinitis, decreasing oxidative stress status }\end{array}$ \\
\hline $\begin{array}{l}\text { Tumour necrosis factor (TNF) rs1800629 } \\
\text { Toll-like receptor 4 (Tlr4) rs1927911 }\end{array}$ & $\begin{array}{l}\text { They are associated with a higher risk of } \\
\text { allergic rhinitis }\end{array}$ \\
\hline
\end{tabular}

of T helper cells, increasing the risk of allergic sensitization [58]. More recently, changes in the expression of small noncoding regulator microRNAs have also been suggested as being critical for mediation of imbalanced responses to allergens [59]. However, to date, it is still unclear what genes and pathways are active during pregnancy and/or at birth and which systems are down- and/or upregulated in response to perinatal OS.

There is increasing evidence that ROS, also at physiologic concentrations, might, acting as cell-signalling mediators and promoting a shift toward a Th2-skewed immune response $[17$,
38], play additional roles in the onset of allergic disorders [17, 38].

The lung, due to its anatomy, provides an extensive surface area available to interact with all sources of reactive $\mathrm{O}_{2}$ species, and a large variety of lung diseases, including allergic asthma, may be induced by ROS $[26,43]$. In particular, pulmonary epithelial cells of alveolar structure appear to be the principle target for oxidant injury which, inhibiting cellular cycle progression, promotes a delayed reepithelialization process and irreversible cellular damage [60]. Moreover, airway inflammatory cells, such as macrophages [61], eosinophils, 
TABLE 3: Oxidative stress-inducible genes and atopic dermatitis.

\begin{tabular}{ll}
\hline Gene & Clinical relevance \\
\hline Glutathione S-transferases- (GSTs-) 1 polymorphism & $\begin{array}{l}\text { It is associated with atopic dermatitis susceptibility in a } \\
\text { Korean population }\end{array}$ \\
\hline $\begin{array}{l}\text { MicroRNA-223 or hypomethylation of the thymic } \\
\text { stromal lymphopoietin (TSLP) gene 59-CpG island } \\
\text { (CGI) }\end{array}$ & $\begin{array}{l}\text { It predisposes the host to development of atopic } \\
\text { dermatitis when combined with exposure to oxidative } \\
\text { stress }\end{array}$ \\
\hline $\begin{array}{l}\text { Tumour necrosis factor (TNF) promoter region } \\
\text { (TNF-a-308G/A) and linked }\end{array}$ & $\begin{array}{l}\text { It is linked to oxidative stress-mediated atopic } \\
\text { dermatitis }\end{array}$ \\
\hline $\begin{array}{l}\text { Nitric oxide polymorphism (T276 (276C/T, nNOS) } \\
\text { C186 (-186A/C, nNOS) + X (CCTTT), nNOS + G954 } \\
(-954 G / C, \text { iNOS) +220 (TAAA), niNOS + G894 }\end{array}$ & $\begin{array}{l}\text { It is related to clinical and functional manifestations of } \\
\text { bronchial asthma and atopic dermatitis }\end{array}$ \\
\hline [894C/G, eNOS) + a (VNTR), eNOs) &
\end{tabular}

and peripheral blood monocytes [40], are themselves a likely source of ROS production [62]. Confirming these findings, studies have shown higher $\mathrm{H}_{2} \mathrm{O}_{2}$, nitric oxide, and superoxide levels in exhaled gases from asthmatic patients than from control subjects [63-66]. A prooxidant status also induces a wide range of biological and molecular damage in the lung. Increased release of isoprostanes and ethane, both in epithelial and in endothelial cell membranes, as well as diminished activity of proteins, such as $\alpha 1$-protease inhibitor, ascorbate, $\alpha$-tocopherol, and superoxide dismutase (SOD), has been reported [67].

Acting on other targets, such as airway smooth muscle, inducing acetylcholine-mediated contraction [68], mucin secretion [69], and nitric oxide- (NO-) mediated neurogenic inflammation [69], ROS can also impair broncho- and vasoregulation [70, 71].

Finally, large-scale genome-wide association studies (GWAS) have demonstrated that genetic susceptibility to allergic asthma is also determined by complex interactions between genes involved in OS, such as glutamate cysteine ligase (GCLM), glutathione peroxidase (GPX1), catalase (CAT), myeloperoxidase (MPO), NADPH oxidase (CYBA, p22phox subunit), $\mathrm{NAD}(\mathrm{P}) \mathrm{H}$, quinone oxidoreductase type 1 (NQO1), and microsomal epoxide hydrolase (EPHX1) [26] (Table 1).

As the primary cell of interface between internal and external environments, nasal mucosal epithelial cells are known to initiate the release of a cascade of proinflammatory mediators through redox pathways [20]. Moreover, these cells also exhibit the capacity to upregulate an effective antioxidant defence [20]. However, natural allergen exposure agents show the ability to interfere with oxidant/antioxidant balance, enhancing OS and upper airway inflammation [72].

Although it has been hypothesized that the role of OS in allergic rhinitis is similar to that of asthma, the exact underlying mechanism is still not understood. However, it has been reported that OS, playing a critical role in allergic asthma, can also contribute to the onset of allergic rhinitis and to enhancing the asthma-rhinitis link, as expression of united airways disease [73].

It has been widely assessed that the loss of antioxidant activities characterizes patients affected by allergic rhinitis. Studies reported that decreased activities of both antioxidant enzyme paraoxonase (PON1) [74] and reduced glutathione
[20] are inversely correlated to plasma total oxidant status and to severity of disease [20]. Consequently, increased nasal fraction of exhaled NO (FENO), 8-isoprostane, leukotriene(LT-) B4, and PGE2 levels was detected in patients with allergic rhinitis [75]. An impaired function and distribution of superoxide anion, NADPH oxidase (NOX)1, and NOX4 in allergic nasal rhinitis has also been noted, as further confirmation of the possible influence of OS on the development of allergic rhinitis [76] (Table 2).

The ability to interfere with the immune system allows ROS to induce and perpetuate skin injury, also in atopic dermatitis. In particular, authors reported that ROS, acting mainly on keratinocytes and partially on lymphocytes [77], induce oxidative protein damage in the stratum corneum, leading to the disruption of barrier functions and the exacerbation of atopic dermatitis [78]. Therefore, in response to a variety of oxidant reactants, the skin upregulates transactivating AP-1 components such as Fos and Jun, whereas it downregulates anti-inflammatory components [79]. Precisely, it has been suggested that upregulation of AP-1 may be associated with a defect in ceramide generation which could result in enhanced protein kinase- $\mathrm{C}$ activation, leading to excessive release of proinflammatory cytokines by keratinocytes [79]. Generally, peroxisome proliferator-activated receptors (PPARs), a member of the nuclear factor family, also influence the biological activity of keratinocytes. To be precise, PPAR isoform- $\alpha$ (PPAR- $\alpha$ ) counteracts the inflammatory response by inhibition of the expression of proinflammatory genes, as well as cytokines and metalloproteases. PPAR- $\alpha$ activation also induces antioxidant enzymes (catalase, SOD) which would reduce oxidative damage and inflammatory response [21].

The oxidant/antioxidant balance is also altered in atopic dermatitis. ROS reduce the physiological antioxidant levels of a number of compounds, such as $\alpha$-tocopherol (VE), ubiquinol-10 (CoQH2-10), ascorbic acid (VC), and glutathione (GSH), in the epidermis and dermis and thus impair the cellular redox system [80]. Evidence of enhanced protein and lipid-oxidative damage was also found in atopic dermatitis patients, as demonstrated by the increase of carbonyl moieties both in lesional and in nonlesional skin, along with higher activity of SOD, an effective scavenger of ROS [81]. Recent experimental studies support a role for 
oxidative/antioxidative imbalance also in the shift toward a Th2-skewed immune response, probably NO-mediated [38]. Accordingly, the administration of antioxidants to human Tcells culture downregulated Th2 polarization, with a decrease in the expression of IL-4 and IL-5, and simultaneous skewing toward a Th1- phenotype [38]. Finally, data suggest epigenetic changes linked to the development of atopic dermatitis through OS-mediated immune dysregulation [82] (Table 3).

\section{Conclusions}

To date, the exact underlying mechanisms of atopic disease are still not understood. Recently, more attention has been given to the critical role of OS-inducible genes in the pathogenesis of atopic diseases. However, in spite of much evidence linking atopic predisposition, inflammatory status, and maternal and neonatal OS, much more remains to be investigated. Moreover, a genomic approach would clarify the role of oxidant/antioxidant pathways, in order to better understand the pathogenesis of atopic diseases and identify innovative therapeutic strategies.

\section{Competing Interests}

The authors have declared no conflict of interests.

\section{Authors' Contributions}

All authors had equally contributed to the manuscript.

\section{References}

[1] C. Anandan, U. Nurmatov, O. C. P. van Schayck, and A. Sheikh, "Is the prevalence of asthma declining? Systematic review of epidemiological studies," Allergy, vol. 65, no. 2, pp. 152-167, 2010.

[2] M. Olivieri, J. Heinrich, V. Schlünssen et al., "The risk of respiratory symptoms on allergen exposure increases with increasing specific IgE levels," Allergy, vol. 71, no. 6, pp. 859868, 2016.

[3] I. Marenholz, J. Esparza-Gordillo, and F. Rüschendorf, "Metaanalysis identifies seven susceptibility loci involved in the atopic march," Nature Communications, vol. 6, no. 6, p. 8804, 2015.

[4] T. A. Manolio, F. S. Collins, N. J. Cox et al., "Finding the missing heritability of complex diseases," Nature, vol. 461, no. 7265, pp. 747-753, 2009.

[5] M. Yamamoto, A. Singh, J. Hirota et al., "Immune-related gene expression profile in human airway epithelium are altered by coexposure to diesel exhaust and allergen," in Proceedings of the American Thoracic Society 2014 International Conference, San Diego, Calif, USA, 2014.

[6] Y. Okayama, "Oxidative stress in allergic and inflammatory skin diseases," Current Drug Targets: Inflammation and Allergy, vol. 4, no. 4, pp. 517-519, 2005.

[7] J. G. O. Ávila, I. Echeverri, C. A. de Plata, and A. Castillo, "Impact of oxidative stress during pregnancy on fetal epigenetic patterns and early origin of vascular diseases," Nutrition Reviews, vol. 73, no. 1, pp. 12-21, 2015.

[8] Y. J. Suzuki, H. J. Forman, and A. Sevanian, "Oxidants as stimulators of signal transduction," Free Radical Biology and Medicine, vol. 22, no. 1-2, pp. 269-285, 1996.
[9] M. S. Williams and J. Kwon, "T cell receptor stimulation, reactive oxygen species, and cell signaling," Free Radical Biology and Medicine, vol. 37, no. 8, pp. 1144-1151, 2004.

[10] M. R. King, A. S. Ismail, L. S. Davis, and D. R. Karp, “Oxidative stress promotes polarization of human $\mathrm{T}$ cell differentiation toward a T helper 2 phenotype," The Journal of Immunology, vol. 176, no. 5, pp. 2765-2772, 2006.

[11] J. M. Morris, N. K. Gopaul, M. J. R. Endresen et al., "Circulating markers of oxidative stress are raised in normal pregnancy and pre-eclampsia," British Journal of Obstetrics and Gynaecology, vol. 105, no. 11, pp. 1195-1199, 1998.

[12] L. Marseglia, G. D’Angelo, S. Manti et al., "Oxidative stressmediated aging during the fetal and perinatal periods," Oxidative Medicine and Cellular Longevity, vol. 2014, Article ID 358375, 8 pages, 2014.

[13] E. Gitto, L. Marseglia, S. Manti et al., "Protective role of melatonin in neonatal diseases," Oxidative Medicine and Cellular Longevity, vol. 2013, Article ID 980374, 6 pages, 2013.

[14] L. Marseglia, G. D’Angelo, S. Manti, R. J. Reiter, and E. Gitto, "Potential utility of melatonin in preeclampsia, intrauterine fetal growth retardation, and perinatal asphyxia," Reproductive Sciences, 2015.

[15] L. Marseglia, S. Manti, G. D’Angelo et al., "Oxidative stress in obesity: a critical component in human diseases," International Journal of Molecular Sciences, vol. 16, no. 1, pp. 378-400, 2015.

[16] L. Marseglia, G. D’Angelo, S. Manti et al., "Oxidative stressmediated damage in newborns with necrotizing enterocolitis: a possible role of melatonin," American Journal of Perinatology, vol. 32, no. 10, pp. 905-909, 2015.

[17] R. P. Bowler and J. D. Crapo, "Oxidative stress in allergic respiratory diseases," Journal of Allergy and Clinical Immunology, vol. 110, no. 3, pp. 349-356, 2002.

[18] L. Marseglia, C. Cuppari, S. Manti et al., "Atopic dermatitis: melatonin as potential treatment," Journal of Biological Regulators and Homeostatic Agents, vol. 29, no. 2, supplement 1, pp. 142-149, 2015.

[19] F. Child, W. Lenney, S. Clayton et al., "The association of maternal but not paternal genetic variation in GSTP1 with asthma phenotypes in children," Respiratory Medicine, vol. 97, no. 12, pp. 1247-1256, 2003.

[20] M. Celik, A. Tuncer, O. U. Soyer, C. Saçkesen, H. Tanju Besler, and O. Kalayci, "Oxidative stress in the airways of children with asthma and allergic rhinitis," Pediatric Allergy and Immunology, vol. 23, no. 6, pp. 556-561, 2012.

[21] M. Y. Sheu, A. J. Fowler, J. Kao et al., "Topical peroxisome proliferator activated receptor- $\alpha$ activators reduce inflammation in irritant and allergic contact dermatitis models," Journal of Investigative Dermatology, vol. 118, no. 1, pp. 94-101, 2002.

[22] H. Batikhan, M. K. Gokcan, E. Beder, N. Akar, A. Ozturk, and M. Gerceker, "Association of the tumor necrosis factoralpha -308 G/A polymorphism with nasal polyposis," European Archives of Oto-Rhino-Laryngology, vol. 267, no. 6, pp. 903-908, 2010.

[23] C.-C. Zou, L.-F. Tang, M.-Z. Jiang, Z.-Y. Zhao, T. Hirokazu, and M. Mitsufumi, "Methylenetetrahydrofolate reductase [correction of reducatase] polymorphism and asthma," Zhonghua Jie He He Hu Xi Za Zhi, vol. 26, no. 3, pp. 161-164, 2003.

[24] M. A. R. Ferreira, A. F. McRae, S. E. Medland et al., "Association between ORMDL3, IL1RL1 and a deletion on chromosome 17q21 with asthma risk in Australia," European Journal of Human Genetics, vol. 19, no. 4, pp. 458-464, 2011. 
[25] M. Tamura and T. Shiroishi, "GSDM family genes meet autophagy," Biochemical Journal, vol. 469, no. 2, pp. e5-e7, 2015.

[26] A. V. Polonikov, V. P. Ivanov, A. D. Bogomazov, M. B. Freidin, T. Illig, and M. A. Solodilova, "Antioxidant defense enzyme genes and asthma susceptibility: gender-specific effects and heterogeneity in gene-gene interactions between pathogenetic variants of the disease," BioMed Research International, vol. 2014, Article ID 708903, 17 pages, 2014.

[27] H.-Y. Cho and S. R. Kleeberger, "Noblesse oblige: NRF2 functions in the airways," American Journal of Respiratory Cell and Molecular Biology, vol. 50, no. 5, pp. 844-847, 2014.

[28] E. Fuertes, M. Brauer, E. MacIntyre et al., "Childhood allergic rhinitis, traffic-related air pollution, and variability in the GSTP1, TNF, TLR2, and TLR4 genes: results from the TAG Study," Journal of Allergy and Clinical Immunology, vol. 132, no. 2, pp. 342-352.e2, 2013.

[29] T. Islam, R. McConnell, W. J. Gauderman, E. Avol, J. M. Peters, and F. D. Gilliland, "Ozone, oxidant defense genes, and risk of asthma during adolescence," American Journal of Respiratory and Critical Care Medicine, vol. 177, no. 4, pp. 388-395, 2008.

[30] M. Panek, T. Pietras, A. Fabijan et al., "Identification and association of the single nucleotide polymorphisms, C-509T, $\mathrm{C}+466 \mathrm{~T}$ and $\mathrm{T}+869 \mathrm{C}$, of the TGF-1 $\beta$ gene in patients with asthma and their influence on the mRNA expression level of TGF- $\beta 1$,' International Journal of Molecular Medicine, vol. 34, no. 4, pp. 975-986, 2014.

[31] M. T. Salam, T. Islam, W. J. Gauderman, and F. D. Gilliland, "Roles of arginase variants, atopy, and ozone in childhood asthma," Journal of Allergy and Clinical Immunology, vol. 123, no. 3, pp. 596-602.e8, 2009.

[32] I.-J. Wang, S.-L. Chen, T.-P. Lu, E. Y. Chuang, and P.-C. Chen, "Prenatal smoke exposure, DNA methylation, and childhood atopic dermatitis," Clinical and Experimental Allergy, vol. 43, no. 5, pp. 535-543, 2013.

[33] S. Hoffjan, I. Ostrovnaja, D. Nicolae et al., "Genetic variation in immunoregulatory pathways and atopic phenotypes in infancy," Journal of Allergy and Clinical Immunology, vol. 113, no. 3, pp. 511-518, 2004.

[34] E. Herrera and H. Ortega-Senovilla, "Lipid metabolism during pregnancy and its implications for fetal growth," Current Pharmaceutical Biotechnology, vol. 15, no. 1, pp. 24-31, 2014.

[35] R. M. Lewis, J. K. Cleal, and M. A. Hanson, "Review: placenta, evolution and lifelong health," Placenta, vol. 33, supplement, pp. S28-S32, 2012.

[36] Ü. Mutlu-Türkoglu, E. Ademoglu, L. Ibrahimoglu, G. AykaçToker, and M. Uysal, "Imbalance between lipid peroxidation and antioxidant status in preeclampsia," Gynecologic and Obstetric Investigation, vol. 46, no. 1, pp. 37-40, 1998.

[37] G. J. Burton and E. Jauniaux, "Oxidative stress," Best Practice \& Research Clinical Obstetrics \& Gynaecology, vol. 25, no. 3, pp. 287-299, 2011.

[38] S. B. Bennett and H. R. Griffiths, Regulation of T-Cell Functions by Oxidative Stress, Springer, Berlin, Germany, 2012.

[39] F. B. Thorén, Å. Betten, A. I. Romero, and K. Hellstrand, "Cutting edge: antioxidative properties of myeloid dendritic cells: protection of T cells and NK cells from oxygen radical-induced inactivation and apoptosis," The Journal of Immunology, vol. 179, no. 1, pp. 21-25, 2007.

[40] M. Mittal, M. R. Siddiqui, K. Tran, S. P. Reddy, and A. B. Malik, "Reactive oxygen species in inflammation and tissue injury," Antioxidants and Redox Signaling, vol. 20, no. 7, pp. 1126-1167, 2014.
[41] H. Ogasawara, S. Yoshimura, and T. Kumoi, "Hydrogen peroxide generation by eosinophils in allergic rhinitis," Auris Nasus Larynx, vol. 18, no. 2, pp. 133-143, 1991.

[42] I. Vachier, M. Damon, C. Le Doucen et al., "Increased oxygen species generation in blood monocytes of asthmatic patients," American Review of Respiratory Disease, vol. 146, no. 5, pp. 11611166, 1992.

[43] S. Aversa, L. Marseglia, S. Manti et al., "Ventilation strategies for preventing oxidative stress-induced injury in preterm infants with respiratory disease: an update," Paediatric Respiratory Reviews, vol. 17, pp. 71-79, 2016.

[44] B. S. Polla, R. Alan Ezekowitz, and D. Y. M. Leung, "Monocytes from patients with atopic dermatitis are primed for superoxide production," The Journal of Allergy and Clinical Immunology, vol. 89, no. 2, pp. 545-551, 1992.

[45] B. M. Willwerth, B. Schaub, K. G. Tantisira et al., "Prenatal, perinatal, and heritable influences on cord blood immune responses," Annals of Allergy, Asthma and Immunology, vol. 96, no. 3, pp. 445-453, 2006.

[46] S. Perrone, R. Bracci, and G. Buonocore, "New biomarkers of fetal-neonatal hypoxic stress," Acta Paediatrica, vol. 91, supplement 438, pp. 135-140, 2002.

[47] G. Devereux, A. Seaton, and R. N. Barker, "In utero priming of allergen-specific helper T cells," Clinical and Experimental Allergy, vol. 31, no. 11, pp. 1686-1695, 2001.

[48] Y. Kitagawa, J. B. Wing, and S. Sakaguchi, "Transcriptional and epigenetic control of regulatory T cell development," in Progress in Molecular Biology and Translational Science, vol. 136, chapter 1, pp. 1-33, Elsevier, 2015.

[49] J. Bousquet, W. Jacot, H. Yssel, A. M. Vignola, and M. Humbert, "Epigenetic inheritance of fetal genes in allergic asthma," Allergy, vol. 59, no. 2, pp. 138-147, 2004.

[50] P. C. J. Janson, M. E. Winerdal, and O. Winqvist, "At the crossroads of $\mathrm{T}$ helper lineage commitment-Epigenetics points the way," Biochimica et Biophysica Acta (BBA)—General Subjects, vol. 1790, no. 9, pp. 906-919, 2009.

[51] P. J. Vuillermin, A.-L. Ponsonby, R. Saffery et al., "Microbial exposure, interferon gamma gene demethylation in naive $\mathrm{T}$ cells, and the risk of allergic disease," Allergy, vol. 64, no. 3, pp. 348-353, 2009.

[52] C. E. West, D. J. Videky, and S. L. Prescott, "Role of diet in the development of immune tolerance in the context of allergic disease," Current Opinion in Pediatrics, vol. 22, no. 5, pp. 635641, 2010.

[53] T. Arrigo, S. Leonardi, C. Cuppari et al., "Role of the diet as a link between oxidative stress and liver diseases," World Journal of Gastroenterology, vol. 21, no. 2, pp. 384-395, 2015.

[54] F. Perera, W.-Y. Tang, J. Herbstman et al., "Relation of DNA methylation of $5^{\prime}-\mathrm{CpG}$ island of ACSL3 to transplacental exposure to airborne polycyclic aromatic hydrocarbons and childhood asthma," PLoS ONE, vol. 4, no. 2, Article ID e4488, 2009.

[55] D. J. Martino and S. L. Prescott, "Silent mysteries: epigenetic paradigms could hold the key to conquering the epidemic of allergy and immune disease," Allergy, vol. 65, no. 1, pp. 7-15, 2010.

[56] J. Liu, M. Ballaney, U. Al-Alem et al., "Combined inhaled diesel exhaust particles and allergen exposure alter methylation of $\mathrm{T}$ helper genes and Ige production in vivo," Toxicological Sciences, vol. 102, no. 1, pp. 76-81, 2008. 
[57] G. Buonocore and S. Perrone, "Biomarkers of oxidative stress in the fetus and newborn," Hematology, vol. 2, no. 10, pp. 103-107, 2006.

[58] J. M. Gostner, K. Becker, D. Fuchs, and R. Sucher, "Redox regulation of the immune response," Redox Report, vol. 18, no. 3, pp. 88-94, 2013.

[59] M. J. Jardim, "microRNAs: implications for air pollution research," Mutation Research/Fundamental and Molecular Mechanisms of Mutagenesis, vol. 717, no. 1-2, pp. 38-45, 2011.

[60] S. Corroyer, B. Maitre, V. Cazals, and A. Clement, "Altered regulation of G1 cyclins in oxidant-induced growth arrest of lung alveolar epithelial cells. Accumulation of inactive cyclin ECDK2 complexes," The Journal of Biological Chemistry, vol. 271, no. 41, pp. 25117-25125, 1996.

[61] W. J. Calhoun, H. E. Reed, D. R. Moest, and C. A. Stevens, "Enhanced superoxide production by alveolar macrophages and air-space cells, airway inflammation, and alveolar macrophage density changes after segmental antigen bronchoprovocation in allergic subjects," The American Review of Respiratory Disease, vol. 145, no. 2, pp. 317-325, 1992.

[62] N. N. Jarjour and W. J. Calhoun, "Enhanced production of oxygen radicals in asthma," Journal of Laboratory and Clinical Medicine, vol. 123, no. 1, pp. 131-136, 1994.

[63] M. Ichinose, H. Sugiura, S. Yamagata, A. Koarai, and K. Shirato, "Increase in reactive nitrogen species production in chronic obstructive pulmonary disease airways," American Journal of Respiratory and Critical Care Medicine, vol. 162, no. 2, pp. 701706, 2000.

[64] K. Ganas, S. Loukides, G. Papatheodorou, P. Panagou, and N. Kalogeropoulos, "Total nitrite/nitrate in expired breath condensate of patients with asthma," Respiratory Medicine, vol. 95, no. 8, pp. 649-654, 2001.

[65] P. Montuschi, M. Corradi, G. Ciabattoni, J. Nightingale, S. A. Kharitonov, and P. J. Barnes, "Increased 8-isoprostane, a marker of oxidative stress, in exhaled condensate of asthma patients," American Journal of Respiratory and Critical Care Medicine, vol. 160, no. 1, pp. 216-220, 1999.

[66] P. Paredi, S. A. Kharitonov, and P. J. Barnes, "Elevation of exhaled ethane concentration in asthma," American Journal of Respiratory and Critical Care Medicine, vol. 162, no. 4, pp. 14501454, 2000.

[67] F. J. Kelly, I. Mudway, A. Blomberg, A. Frew, and T. Sandstrom, "Altered lung antioxidant status in patients with mild asthma," The Lancet, vol. 354, no. 9177, pp. 482-483, 1999.

[68] U. Katsumata, M. Miura, M. Ichinose et al., "Oxygen radicals produce airway constriction and hyperresponsiveness in anesthetized cats," American Review of Respiratory Disease, vol. 141, no. 5, pp. 1158-1161, 1990.

[69] D. T. Wright, B. M. Fischer, C. Li, L. G. Rochelle, N. J. Akley, and K. B. Adler, "Oxidant stress stimulates mucin secretion and PLC in airway epithelium via a nitric oxide-dependent mechanism," American Journal of Physiology-Lung Cellular and Molecular Physiology, vol. 271, no. 5, pp. L854-L861, 1996.

[70] C. M. Prado, M. A. Martins, and IF. Tibério, "Nitric oxide in asthma physiopathology," ISRN Allergy, vol. 2011, Article ID 832560, 13 pages, 2011.

[71] H. Sugiura and M. Ichinose, "Nitrative stress in inflammatory lung diseases," Nitric Oxide, vol. 25, no. 2, pp. 138-144, 2011.

[72] C. Gratziou, N. Rovina, M. P. Makris, D. C. M. Simoes, A. Papapetropoulos, and C. Roussos, "Breath markers of oxidative stress and airway inflammation in Seasonal Allergic Rhinitis,"
International Journal of Immunopathology and Pharmacology, vol. 21, no. 4, pp. 949-957, 2008.

[73] M. Profita, P. Montuschi, A. Bonanno et al., "Novel perspectives in the detection of oral and nasal oxidative stress and inflammation in pediatric united airway diseases," International Journal of Immunopathology and Pharmacology, vol. 23, no. 4, pp. 12111219, 2010.

[74] E. Ozkaya, H. Akduman, U. Erenberk, A. Demir, and M. R. Dundaroz, "Plasma paraoxonase activity and oxidative stress and their relationship to disease severity in children with allergic rhinitis," American Journal of Rhinology and Allergy, vol. 27, no. 1, pp. 13-17, 2013.

[75] K. Tanou, A. Koutsokera, T. S. Kiropoulos et al., "Inflammatory and oxidative stress biomarkers in allergic rhinitis: the effect of smoking," Clinical and Experimental Allergy, vol. 39, no. 3, pp. 345-353, 2009.

[76] J. H. Moon, T. H. Kim, H. M. Lee et al., "Overexpression of the superoxide anion and NADPH oxidase isoforms 1 and 4 (NOX1 and NOX4) in allergic nasal mucosa," American Journal of Rhinology \& Allergy, vol. 23, no. 4, pp. 370-376, 2009.

[77] C. Albanesi and S. Pastore, "Pathobiology of chronic inflammatory skin diseases: interplay between keratinocytes and immune cells as a target for anti-inflammatory drugs," Current Drug Metabolism, vol. 11, no. 3, pp. 210-227, 2010.

[78] Y. Niwa, H. Sumi, K. Kawahira, T. Terashima, T. Nakamura, and H. Akamatsu, "Protein oxidative damage in the stratum corneum: evidence for a link between environmental oxidants and the changing prevalence and nature of atopic dermatitis in Japan," British Journal of Dermatology, vol. 149, no. 2, pp. 248254, 2003.

[79] Ö. Uluçkan, J. Guinea-Viniegra, M. Jimenez, and E. F. Wagner, "Signalling in inflammatory skin disease by AP-1 (Fos/Jun)," Clinical and Experimental Rheumatology, vol. 33, no. 4, supplement 92, pp. S44-S49, 2015.

[80] Y. Yamamoto, "Role of active oxygen species and antioxidants in photoaging," Journal of Dermatological Science, vol. 27, no. 1, pp. S1-S4, 2001.

[81] J. Fuchs, T. M. Zollner, R. Kaufmann, and M. Podda, "Redoxmodulated pathways in inflammatory skin diseases," Free Radical Biology and Medicine, vol. 30, no. 4, pp. 337-353, 2001.

[82] Early Genetics and Lifecourse Epidemiology (EAGLE) Eczema Consortium, "Australian Asthma Genetics Consortium(AAGC); Australian Asthma Genetics Consortium AAGC. Multiancestry genome-wide association study of 21,000 cases and 95,000 controls identifies new risk loci for atopic dermatitis," Nature Genetics, vol. 47, no. 12, pp. 1449-1456, 2015. 


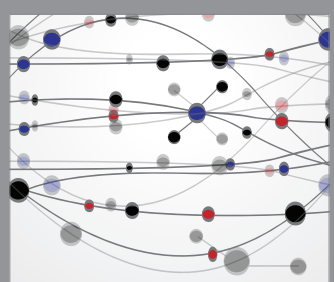

The Scientific World Journal
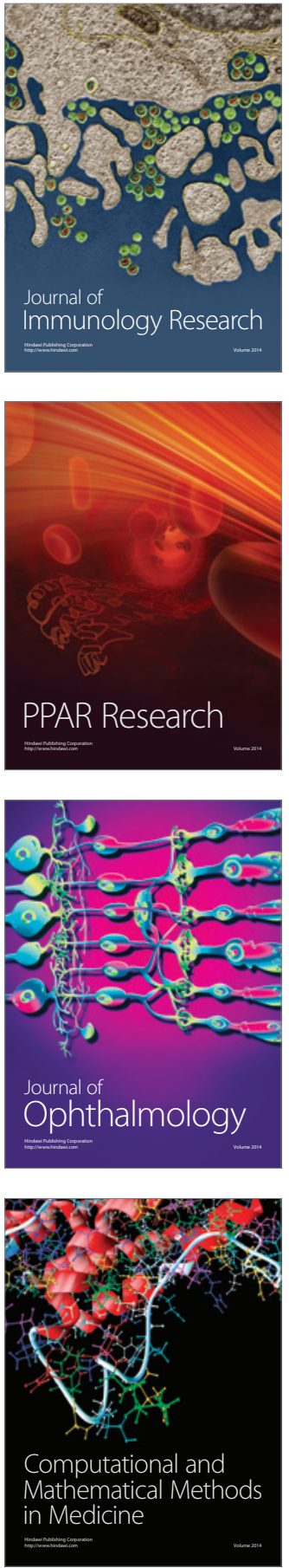

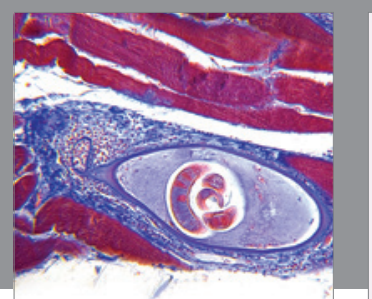

Gastroenterology Research and Practice

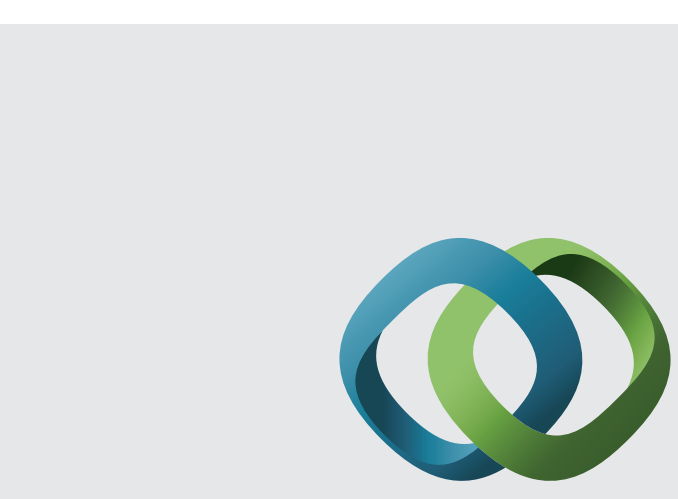

\section{Hindawi}

Submit your manuscripts at

http://www.hindawi.com
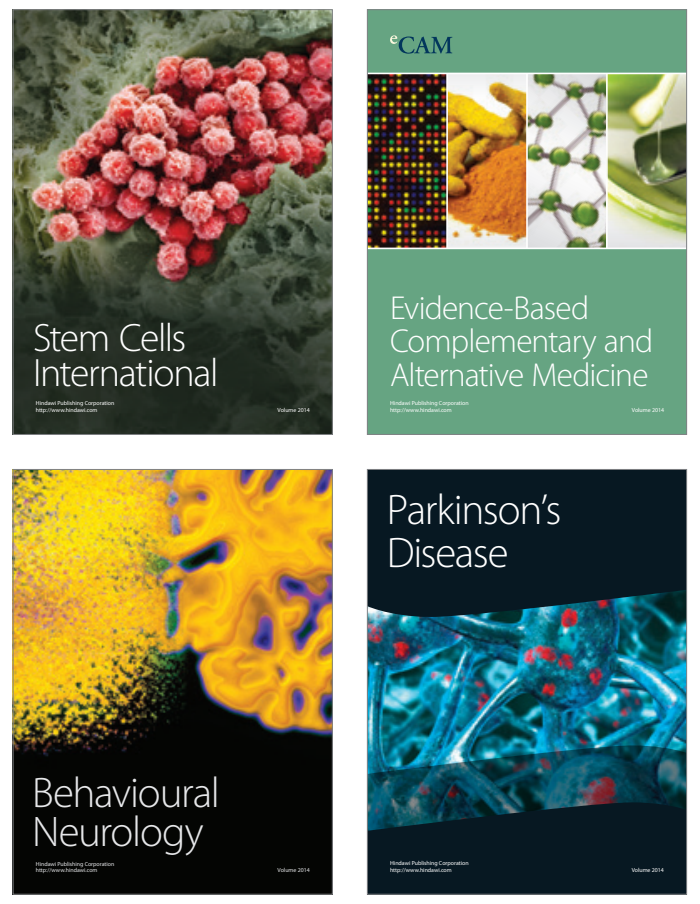
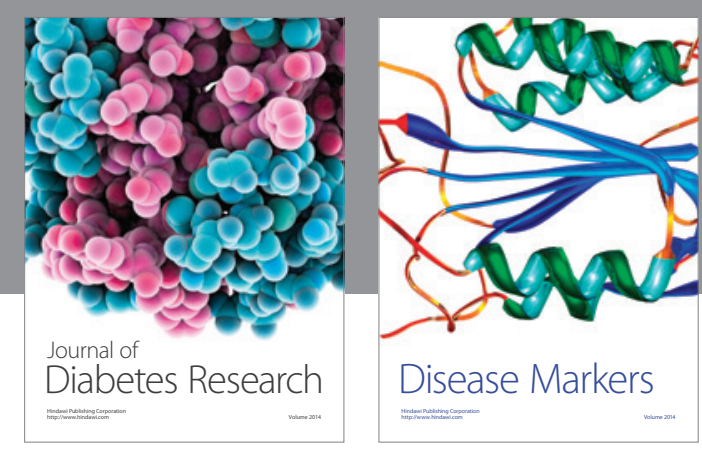

Disease Markers
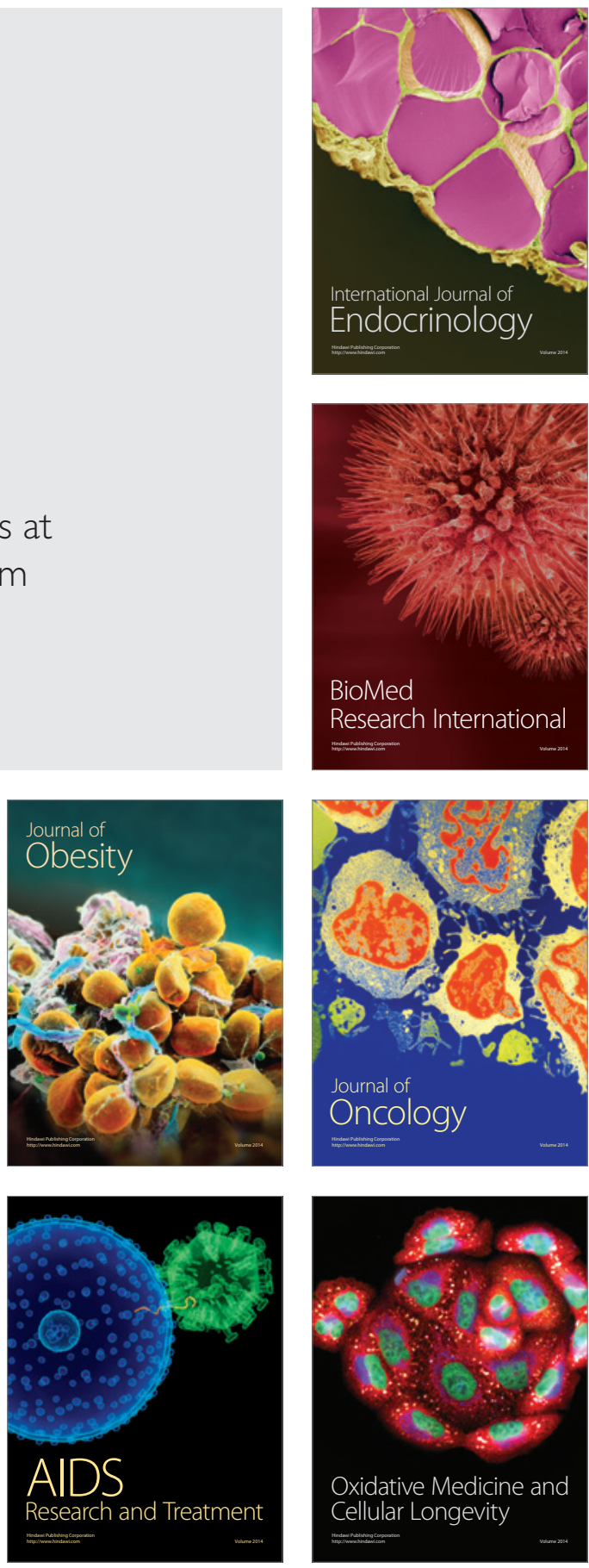